\title{
MANIFIESTO (HABLO POR MI DIFERENCIA)
}

\section{Pedro Lemebel}

No soy Pasolini pidiendo explicaciones

No soy Ginsberg expulsado de Cuba

No soy un marica disfrazado de poeta

No necesito disfraz

Aquí está mi cara

Hablo por mi diferencia

Defiendo lo que soy

Y no soy tan raro

Me apesta la injusticia

Y sospecho de esta cueca democrática

Pero no me hable del proletariado

Porque ser pobre y maricón es peor

Hay que ser ácido para soportarlo

Es darle un rodeo a los machitos de la esquina

Es un padre que te odia

Porque al hijo se le dobla la patita

Es tener una madre de manos tajeadas por el cloro

Envejecidas de limpieza

Acunándote de enfermo

Por malas costumbres

Por mala suerte

Como la dictadura

Peor que la dictadura

Porque la dictadura pasa

Y viene la democracia

Y detrasito el socialismo

¿Y entonces?

¿Qué harán con nosotros compañero?

¿Nos amarrarán de las trenzas en fardos

con destino a un sidario cubano?

Nos meterán en algún tren de ninguna parte

Como en el barco del general Ibáñez

Donde aprendimos a nadar

Pero ninguno llegó a la costa

Por eso Valparaíso apagó sus luces rojas

Por eso las casas de caramba

Le brindaron una lágrima negra 
A los colizas comidos por las jaibas

Ese año que la Comisión de Derechos Humanos no recuerda

Por eso compañero le pregunto ¿Existe aún el tren siberiano de la propaganda reaccionaria? Ese tren que pasa por sus pupilas Cuando mi voz se pone demasiado dulce ¿Y usted?

¿Qué hará con ese recuerdo de niños

Pajeándonos y otras cosas

En las vacaciones de Cartagena?

¿El futuro será en blanco y negro?

¿El tiempo en noche y día laboral

sin ambigüedades?

¿No habrá un maricón en alguna esquina

desequilibrando el futuro de su hombre nuevo?

¿Van a dejarnos bordar de pájaros

las banderas de la patria libre?

El fusil se lo dejo a usted

Que tiene la sangre fría

Y no es miedo

El miedo se me fue pasando

De atajar cuchillos

En los sótanos sexuales donde anduve

Y no se sienta agredido

Si le hablo de estas cosas

Y le miro el bulto

No soy hipócrita

¿Acaso las tetas de una mujer

no lo hacen bajar la vista?

¿No cree usted

que solos en la sierra

algo se nos iba a ocurrir?

Aunque después me odie

Por corromper su moral revolucionaria

¿Tiene miedo que se homosexualice la vida?

Y no hablo de meterlo y sacarlo

Y sacarlo y meterlo solamente

Hablo de ternura compañero

Usted no sabe

Cómo cuesta encontrar el amor

En estas condiciones 
Usted no sabe

Qué es cargar con esta lepra

La gente guarda las distancias

La gente comprende y dice:

Es marica pero escribe bien

Es marica pero es buen amigo

Súper-buena-onda

Yo no soy buena onda

Yo acepto al mundo

Sin pedirle esa buena onda

Pero igual se ríen

Tengo cicatrices de risas en la espalda

Usted cree que pienso con el poto

Y que al primer parrillazo de la CNI

Lo iba a soltar todo

No sabe que la hombría

Nunca la aprendí en los cuarteles

Mi hombría me la enseñó la noche

Detrás de un poste

Esa hombría de la que usted se jacta

Se la metieron en el regimiento

Un milico asesino

De esos que aún están en el poder

Mi hombría no la recibí del partido

Porque me rechazaron con risitas

Muchas veces

Mi hombría la aprendí participando

En la dura de esos años

Y se rieron de mi voz amariconada

Gritando: Y va a caer, y va a caer

$Y$ aunque usted grita como hombre

No ha conseguido que se vaya

Mi hombría fue la mordaza

No fue ir al estadio

Y agarrarme a combos por el Colo Colo

El fútbol es otra homosexualidad tapada

Como el box, la política y el vino

Mi hombría fue morderme las burlas

Comer rabia para no matar a todo el mundo

Mi hombría es aceptarme diferente

Ser cobarde es mucho más duro

Yo no pongo la otra mejilla

Pongo el culo compañero 
Y ésa es mi venganza

Mi hombría espera paciente

Que los machos se hagan viejos

Porque a esta altura del partido

La izquierda tranza su culo lacio

En el parlamento

Mi hombría fue difícil

Por eso a este tren no me subo

Sin saber dónde va

Yo no voy a cambiar por el marxismo

Que me rechazó tantas veces

No necesito cambiar

Soy más subversivo que usted

No voy a cambiar solamente

Porque los pobres y los ricos

A otro perro con ese hueso

Tampoco porque el capitalismo es injusto

En Nueva York los maricas se besan en la calle

Pero esa parte se la dejo a usted

Que tanto le interesa

Que la revolución no se pudra del todo

A usted le doy este mensaje

Y no es por mí

Yo estoy viejo

Y su utopía es para las generaciones futuras

Hay tantos niños que van a nacer

Con una alíta rota

Y yo quiero que vuelen compañero

Que su revolución

Les dé un pedazo de cielo rojo

Para que puedan volar.

NOTA: Este texto, íntegro en su gramática y ortografía, fue leído como intervención en un acto político de la izquierda en septiembre de 1986, en Santiago de Chile. Véase: Lemebel, Pedro, Loco Afán, Crónicas de sidario, Santiago: Lom Ediciones, 1997, págs. 83-90. (N. del E.) 